\title{
Numerical Investigation of Boiler Tubes Performance of Heat Transfer Enhancement with Varying Shapes of Corrugated Tube
}

\author{
Bhavna Singh*, Sanjay Kumar*, Vimal Singh Chamyal*, Mohit Pant*, Tarun \\ Tripathi*, Shivasheesh Kaushik ** \\ *(Research Scholar, Mechanical Engineering Department, Amrapali Group of Institute, Haldwani, Uttarakhand, India \\ (Main Authors)) \\ ** (Assistant Professor, Mechanical Engineering Department, Amrapali Group of Institute, Haldwani, Uttarakhand, \\ India Email: shivasheeshkaushik@gmail.com (Corresponding Author))
}

\begin{abstract}
The convective heat transfer of flow in corrugated channels has been investigated using a commercial CFD tool. Heat transfer enhancement of corrugated tube was mainly taken into consideration. Performance of corrugated geometry of the tube was studied by varying its influencing geometrical parameters like number of rifling, height of rifling, length of pitch of rifling for a particular length. The effects of the different geometry of the corrugation, such as circular, rectangular and triangular geometry and heat transfer were determined for flow through tube heat exchanger. The change in corrugation shape gave substantial change in heat transfer rate. The result reveals the effect on corrugation effect on heat transfer rate. The result shows that the heat transfer increased when compared with existing inner plan wall water tube.
\end{abstract}

Keywords: Boiler tube, Heat transfer enhancement, corrugated geometry, Multi-rifled tube, helical tube

\section{INTRODUCTION}

Boiler supply the major source in industries to burn fuel to generate electric power and process steam. It is the main device of power plant to generate steam by efficiently burning available fuels used to generation of power. The steam can be used for various usages such as driving an engine to generate electricity, heating purpose and for other industrial process applications. The boiler consists of several types, which include water tube boiler, fire tube boiler, packaged boiler, fluidized bed combustion (FBC) boiler, atmospheric fluidized bed combustion (AFBC) boiler and so forth. The main objective of this study is linked to the idea of being able to model the temperature fluctuations that occur in the evaporator tubes. These temperatures are initiated by wall Numerical investigation of Boiler tubes for performance enhancement temperatures as well as the heat flux from the furnace. Therefore a basic understanding of the fluid dynamics as well as material conditions in the form of heat transfer is essential in this work. The main objective of report is to describe and analyze the knowledge about operational flexibility in boiler tube, based on mathematical / numerical methods. More specifically, the report aims to:

Examine the advantages and disadvantages in using internal rifled boiler tubes in steam power plants. Obtain a detailed understanding of the phenomena leading to flow mal-distribution under different operating conditions. To study the flow pattern inside the rifled tube.
The most popular boilers that used in many industries are water tube and fire tube boiler. Water tube boiler is the one with water flowing through the tubes that enclosed in a furnace heated externally while fire tube boiler comprises of fire or hot flue gas directed through tubes surrounded by water. Conversion process of water into steam in a large scale industrial boiler involves a large amount of operating cost. Due to economic and environment concern, engineers must continuously focus on improving efficiency of steam production and reduce emission with the same amount of fuel (Steingress 1970). It is done by increasing the heating surface area in contact with the water. This enables the heat to be fully utilized and not lost to surrounding. High thermal exposure and inefficient heat transfer from the flue gas into the water contained in water tubes due to the development of scales on the internal tube wall results in creep formation. The boiler tubes condition worsen with wall thinning effect on the exterior tube wall as it promotes higher hoop stress on the tube and thus, shortens the life span of the tubes. With the existence and interaction between thick scales and wall thinning, the life span of the tubes could further reduced. In real condition the boiler water tube are plane wall, due to this the flow is laminar inside the tube. The establishment of corrugated geometry obtained with roughened surface like internal helical ridging or transverse ribbing or multi rifled tubes to increase the heat transfer in tubes. Most studies have concentrated on turbulent flow; the laminar range is of particular 
interest in wide variety of engineering situations, counting heat exchangers for viscous liquids in food industry and chemical process. The use of smooth surface inside the tubes gives poor performances and new geometries are needed to enhance the rate of heat transfer in tubes. Numerical investigation of Boiler tubes for performance enhancement. The proper designs of the tube inner wall will increase the heat transfer to the flowing water; hence it is one of the main factors for its successful usage in boiler. In order to increase the heat transfer and prevent damage to the inner wall of tube, ribbed tubes are applied instead of the smooth walled tubes. Surface roughness introduces through knurling or threading or formed by repeated ribs, promotes enhancement through the disturbance of the sub layer that is close to the surface. The heat transfer coefficient is one of the most important factors for the successful design and operation of inner tube wall to heat transfer on the flowing water. Analysis and modeling of the inner tube wall for boiler is very important, in order to keep the boiler operation below the critical stages. Ali and Ramadhyani (1992) conducted experiments to analyze the developing flow region of corrugated channels. They examined laminar and transitional flow for two different inter-wall spacing. For both channels, they observed a transition to unsteady flow at $\operatorname{Re} \sim 500$, accompanied by a sharp increase in Nusselt number. As a result, optimal heat transfer enhancement was found to occur in the transitional flow regime. No substantial enhancement was detected when the flow was steady. . Cheng, L. X. \& Chen, T. K. (2001) had conducted experimental work of flow boiling heat transfer and two-phase flow frictional pressure drop in a vertical rifled tube and smooth tube under the condition of 0.6 MPa. The rifled tube that was used in the experiment had an outside diameter $22 \mathrm{~mm}$, average inner diameter $11.6 \mathrm{~mm}$ rib width $5.5 \mathrm{~mm}$, rib height $0.4 \mathrm{~mm}$ $0.6 \mathrm{~mm}$ and rib pitch $3.5 \mathrm{~mm}$. Nonetheless, the outside and inside diameters of the smooth tube are $19 \mathrm{~mm}$ and $15 \mathrm{~mm}$. The results of the experiment had shown that the flow boiling heat transfer coefficient and two-phase frictional pressure drop in rifled tube were $1.4-2.0$ times and $1.6-2.0$ times, respectively than in the smooth tube. It was interesting to note that the superheat wall temperatures in the rifled tube are smaller than in the smooth tube under equal heat fluxes and equal mass fluxes. The authors had also found out that the flow boiling heat transfer coefficient would increase if the mass flux increase, but the pressures had little effect on the flow boiling heat transfer coefficient. Correlations of flow boiling heat transfer coefficient and two-phase frictional pressure drop in the rifled tube also had been proposed. The advantage of the rifled tube compare to smooth tube is that it will cause the swirling effect in the flow. They also act like a roughness elements mixing up the flow in the viscous sub layer (Kundu, P. K. \& Cohen, I. M., 2004). Besides that due to its inner geometry shape, flow is thrown outwards to the tube wall as a result of centrifugal action. Thus, creates a secondary flow or also known as helical flow or a swirl flow at the near wall region. This helical flow at the tube periphery superimpose on the main axial flow. This effect enhance wall wetting and prevents critical heat transfer occurrence even under high steam void fraction conditions and lower critical heat flux. As a result, this type of tube would not easily burnout and can be used under much higher operating condition than the smooth tube. C. H. Kim et al. (2005) had evaluated the critical heat flux (CHF) performance for flow boiling of R134a in vertical uniformly heated smooth tube and rifled tube. In this experimental work, a four head and sixhead rifled tube with outer diameter $22.59 \mathrm{~mm}$ and minimum inner diameter ranging between $15.22 \mathrm{~mm}$ - $15.39 \mathrm{~mm}$ had been used under outlet pressures of 13, 16.5 and 23.9 bar, mass fluxes of 285 $1300 \mathrm{~kg} / \mathrm{m} 2 \mathrm{~s}$ and inlet sub cooling temperature ranging $5-40^{\circ} \mathrm{C}$. It is concluded that the $\mathrm{CHF}$ enhancement in the rifled tube had been enhanced $40 \%$ - $60 \%$ than in the smooth tube. The CHF enhancement not only depends on the mass flux and pressure, but there is also a critical helical angle and critical velocity to get the $\mathrm{CHF}$ enhancement. The author had explained the CHF enhancement by using the relative velocity of vapor and it is interesting to note that when the flow pressure is near critical pressure, the helical angle is above $70 \mathrm{o}$ and the velocity is below $0.3 \mathrm{~m} / \mathrm{s}$, the centrifugal acceleration will be decreased. As a result, the flow inside the rifled tube would be ceased to follow the ribs and the swirling flow is diminished. Numerical investigation of Boiler tubes for performance enhancement Lee, S. K. \& Chang, S. H. (2008) had studied experimentally the post dry-out with R- 134a upward flow in smooth tube and rifled tube. The authors had used three type of rifled tube which had 4 head, helix angle $60^{\circ}$ and maximum inside diameter of $17.04 \mathrm{~mm}$ with an average volume based inner diameter of $16.49 \mathrm{~mm}, 16.05 \mathrm{~mm}$ and $16.79 \mathrm{~mm}$, respectively. From these three types of rifled tube, the authors then had examined the effects of rib geometry and compared with the smooth tube. The smooth tube that was used in the study had an average inner diameter of $17.04 \mathrm{~mm}$ and outside diameter of $22.59 \mathrm{~mm}$. It is found out that the wall temperature of the rifled tube in the post-dry out region were much smaller than the smooth tube. As a result, the thermal non-equilibrium in rifled tube was lowered which due to the swirling flow was caused by the ribs in the rifled tube. The authors had also stated correlation of heat transfer for rifled tube as a function of rib height and rib width. O'Brien and Sparrow (1982) conducted one of the first 
comprehensive studies for the fully-developed region of a corrugated channel for flow in the range of $1500<\operatorname{Re}<25,000$. They observed heat transfer rates that were approximately 2.5 times greater than for the straight channel. But the pressure drop for the corrugated duct was significantly larger as well. Sparrow and Comb (1983) performed a similar study for a corrugated channel with an inter-wall spacing that was approximately $45 \%$ greater than the channel used by O'Brien and Sparrow (1982), and then analyzed the effects of this variation. The increase in spacing led to a $30 \%$ rise in the fully-developed Nusselt number, but the friction factor more than doubled. To Numerical investigation of Boiler tubes for performance enhancement further assess these findings, performance evaluations were carried out for three different constraints. For all three cases, the performance differences between the two ducts were not sufficiently great to indicate a clear superiority of one over the other.

\section{METHODOLOGY}

The methodology of the present study can be divided into four stages of process flow which are geometry modeling, pre-processing, processing and post-processing. Various steps in adopted methods are:

- Mathematical modeling of the system considered in present study.

- Developed the model in SOLIDWORKS.

- Validation of present work with previous research.

- Calculation of heat transfer parameters.

- Run program to obtain the plots with different boiler tube parameters.

- Plotting \& analysis of obtained plots.

- Optimization of the system.

\section{SIMULATION OF FLOW} THROUGH BOILER TUBE

For the CFD analysis of boiler tube, three different geometry of tube were used, the first geometry used was Circular rib, the second one was the rectangular rib and the third one was triangular rib geometry, the boundary conditions applied to the channel, the assumptions made, the equations used, the results obtained after calculation and then the results were compared with the smooth geometry.

\section{FLOW AND HEAT TRANSFER IN BOILER TUBE \\ 4.1 Geometrical Description}

The geometry created for analysis were three different types of corrugated tubes which was made of steel of $160 \mathrm{~cm}$ length and has hydraulic diameter of $6.05 \mathrm{~cm}$ in which fluid flow occurs. Corrugations made on the tubes were chevron design and the wave design. These geometrical models of plates are used for studying the effects of the variation of Reynolds number on the performance of plate heat exchanger. The different geometries of the tubes are shown in figure 4.1.

\section{RESULT AND DISCUSSION}

The mathematical model and methodology for solving the problem used in present work is discussed in previous chapter. This mathematical model is studied, solved and validated using a ANSYS (FLUENT) programme in the present work. Present work also includes parametric study of boiler tube geometry and obtaining heat transfer characteristics of boiler tube with different geometry and compared it with the smooth tube. Simulations were carried out with constant mass flow rate for all the geometries considered here for boiler tube. The post processor was carried out in Fluent, and during the process, the following observations were encountered. As discussed in Chapter-4, $160 \mathrm{~cm}$ length and diameter of $6.08 \mathrm{~cm}$ of three boiler tube geometry are taken for the simulation in present work. The other parameters have to be calculated in order to optimize the complete system. Following sections describes the parametric study and the optimization of the system.

\subsection{Effect of corrugated geometry on heat transfer enhancement in boiler tube}

Table below shows different parameters of heat transfer enhancement in boiler tube having smooth tube and other three different geometry. It has been observed that the total heat transfer rate, temperature and enthalpy at the outlet of the channel is increased significantly by applying corrugated geometry inside the tube of boiler. This is due to expanded roughness surface area for similar mass flow inlet. Lower the low value of mass flow inlet higher will be the surface area and tube get heated consistently and in relatively minimum time as compare to large mass flow inlet and smooth tube.

\subsection{Temperature Profiles of boiler tube}

When fluid to be heated enters into the tube, due to convective heat transfer the fluid inside the tube get heated. Due to wall heat transfer coefficient and area product fluid get heated initially up to a certain length and after a long time fluid reaches to a consistent temperature. Once fluid gets converted into steam it is now available to supply where needed. Below are the some graphs showing temperature profile against the position of the tube. From the graph as shown above, it is been observed that the graph showing temperature profile of smooth tube having simple geometry is not efficient as compared to the graph of other figures having corrugated geometry. Temperature of smooth tube geometry goes up to $396 \mathrm{~K}$ from initial temperature of $300 \mathrm{~K}$ while the temperature of corrugated tube 

ISSN : 2248-9622, Vol. 7, Issue 4, ( Part -5) April 2017, pp.46-54

having rectangular, triangular, and circular geometry goes up to $415 \mathrm{~K}, 418 \mathrm{~K}$, and $411 \mathrm{~K}$ respectively. The mean temperature of the working fluid increases with the distance from the entrance as expected, as shown in figure 5.5. Also expected, the increase is rapid nearer the wall because of high heat transfer rates in this region due to higher temperature differences between the wall surface and the fluid.

\section{FIGURES AND TABLES}

Table 4.1 The dimension of rifled tube geometry parameters

\begin{tabular}{|l|l|}
\hline Tube type & Helical ridging \\
\hline $\begin{array}{l}\text { Outer diameter, Do } \\
(\mathrm{mm})\end{array}$ & $6.08 \mathrm{~cm}$ \\
\hline Helix Angle & $35^{\circ}$ \\
\hline Length & $160 \mathrm{~cm}$ \\
\hline Tube Material & Copper \\
\hline Length of Pitch & $35 \mathrm{~cm}$ \\
\hline Height of rifling & $0.15 \mathrm{~cm}$ \\
\hline
\end{tabular}

FLOW CHART SHOWING THE APPROACH FOR SOLVING THE PROBLEM

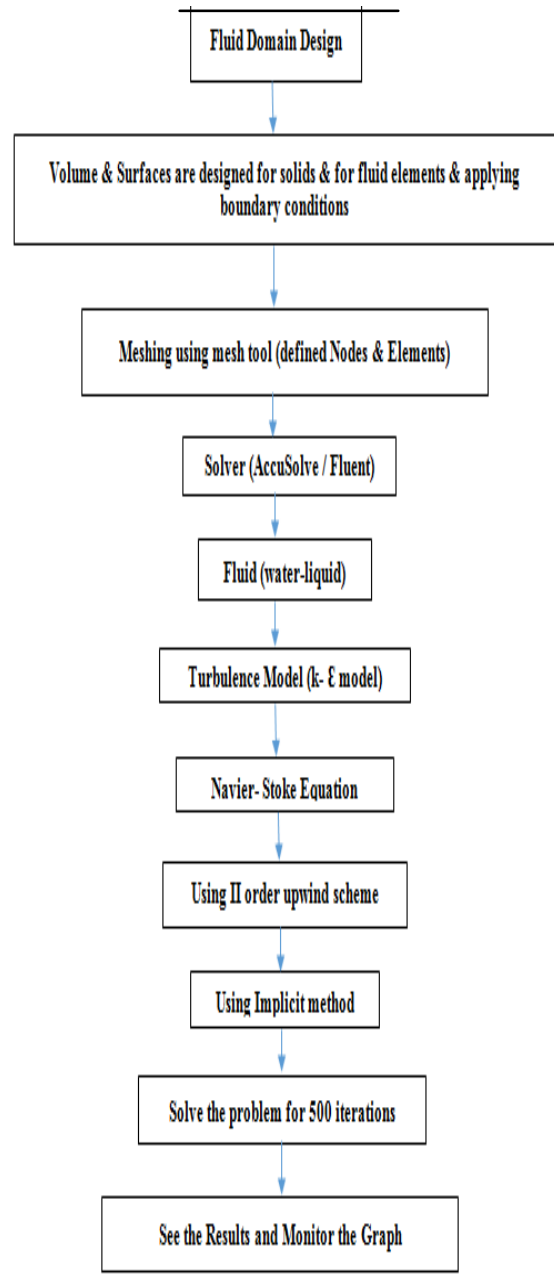

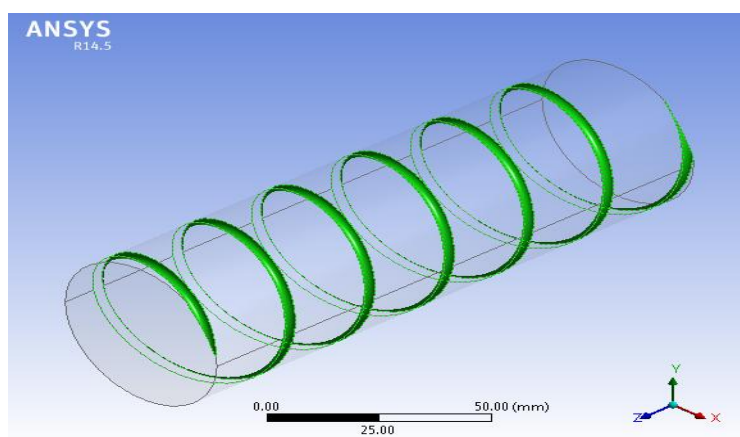

Fig 4.1 (a) Helical (circular) ridging inside the tube

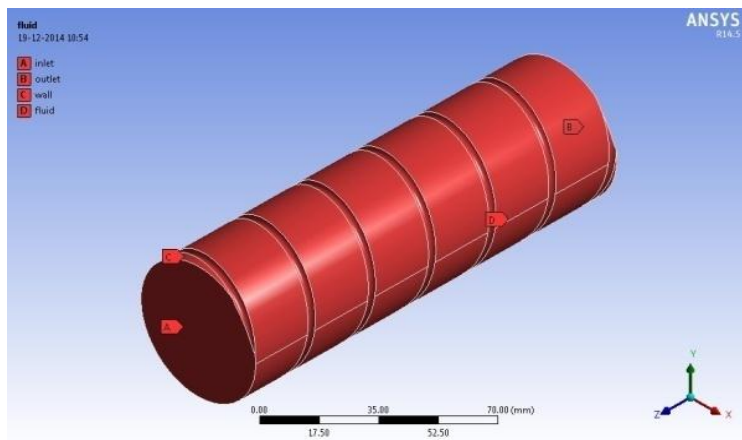

Fig 4.1 (b) Model showing various parts of the tube

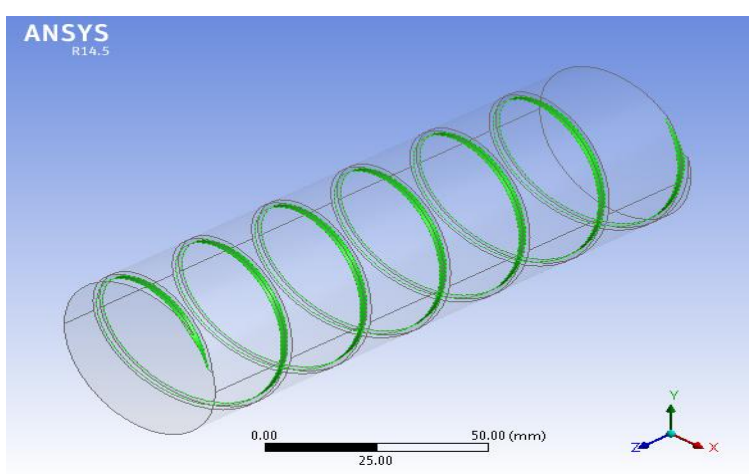

Fig 4.1 (c) Helical (rectangular) ridging inside the tube

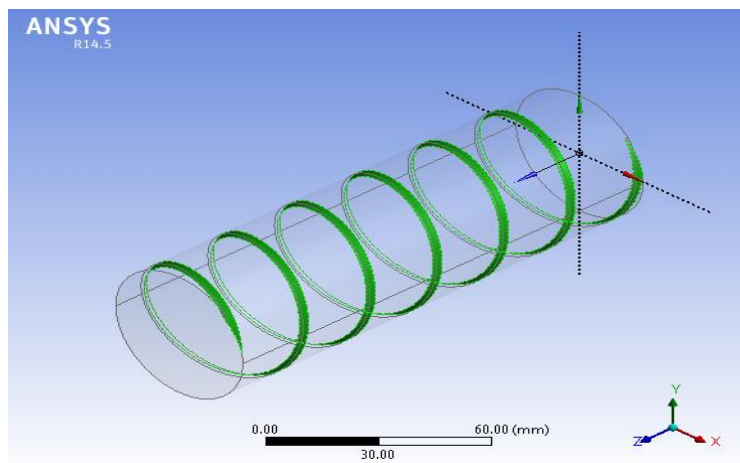

Fig 4.1 (d) Helical (triangular) ridging inside the tube 

ISSN : 2248-9622, Vol. 7, Issue 4, ( Part -5) April 2017, pp.46-54

Table 5.1 Different sets of boiler tube parameters having simple geometry

\begin{tabular}{|l|l|l|}
\hline Type Inlet & Outlet \\
\hline $\begin{array}{l}\text { Total Heat Transfer } \\
\text { Rate (W) }\end{array}$ & 438.10 & 3418.92 \\
\hline Temperature (K) & 300 & 396 \\
\hline $\begin{array}{l}\text { Heat Transfer } \\
\left.\text { Coefficient (W/m }{ }^{2}-\mathrm{K}\right)\end{array}$ & & 2763.5 \\
\hline
\end{tabular}

Table 5.2 Different sets of boiler tube parameters having circular geometry

\begin{tabular}{|l|l|l|}
\hline Type & Inlet & Outlet \\
\hline $\begin{array}{l}\text { Total Heat Transfer } \\
\text { Rate (W) }\end{array}$ & 275.14 & 5962.395 \\
\hline Temperature (K) & 300 & 411.878 \\
\hline $\begin{array}{l}\text { Heat Transfer } \\
\left.\text { Coefficient (W/m }{ }^{2}-\mathrm{K}\right)\end{array}$ & & 4768.98 \\
\hline
\end{tabular}

Table 5.3 Different sets of boiler tube parameters having rectangular geometry

\begin{tabular}{|l|l|l|}
\hline Type & Inlet & Outlet \\
\hline $\begin{array}{l}\text { Total Heat Transfer } \\
\text { Rate (W) }\end{array}$ & 268.55 & 6912.385 \\
\hline Temperature (K) & 300 & 413.98 \\
\hline $\begin{array}{l}\text { Heat Transfer } \\
\left.\text { Coefficient (W/m }{ }^{2}-\mathrm{K}\right)\end{array}$ & & 5488.08 \\
\hline
\end{tabular}

Table 5.4 Different sets of boiler tube parameters having triangular geometry

\begin{tabular}{|l|l|l|}
\hline Type & Inlet & Outlet \\
\hline $\begin{array}{l}\text { Total Heat } \\
\text { Transfer Rate (W) }\end{array}$ & 279.582 & 6709.544 \\
\hline Temperature (K) & 300 & 418.0129 \\
\hline & & 5322.3 \\
\hline
\end{tabular}

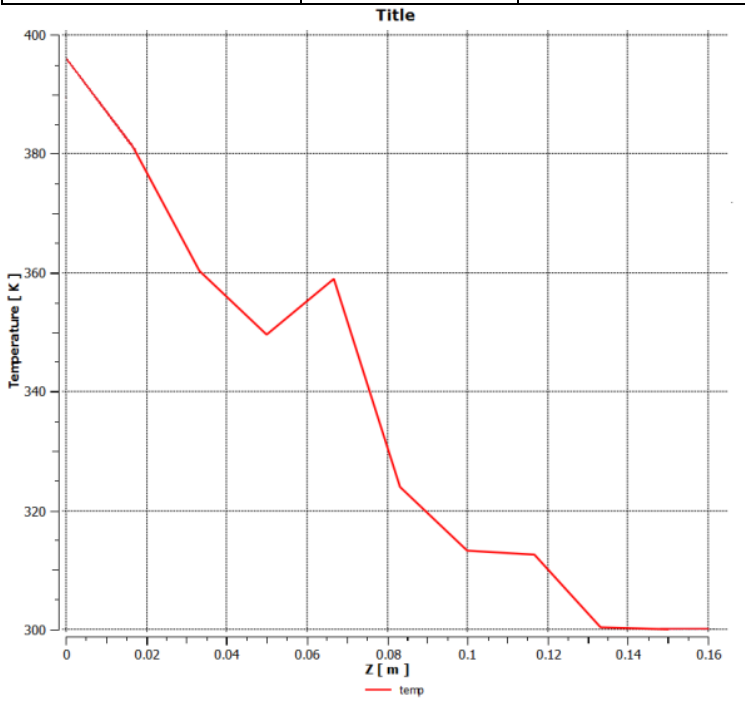

Fig. 5.1(a) Variation of temperature profile with the position of the tube for smooth tube having plane geometry.

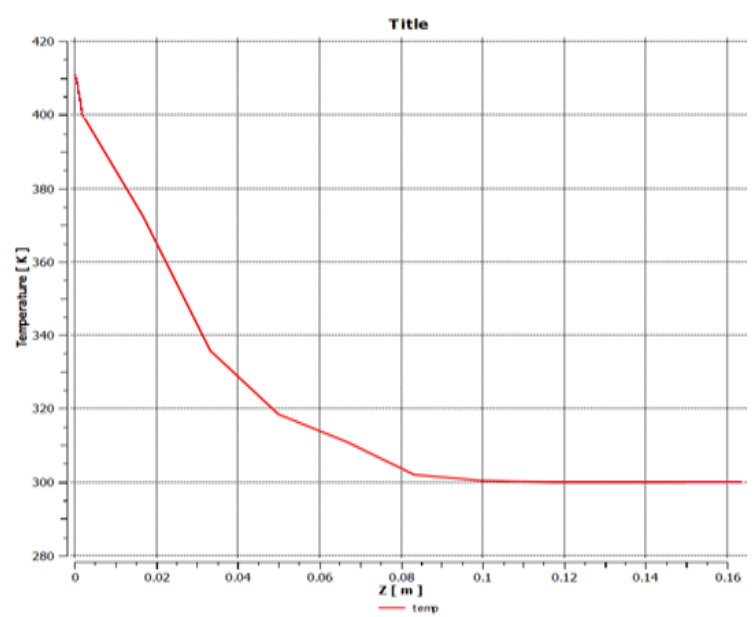

Fig. 5.2(b) Variation of temperature profile with the position of the tube for circular geometry.

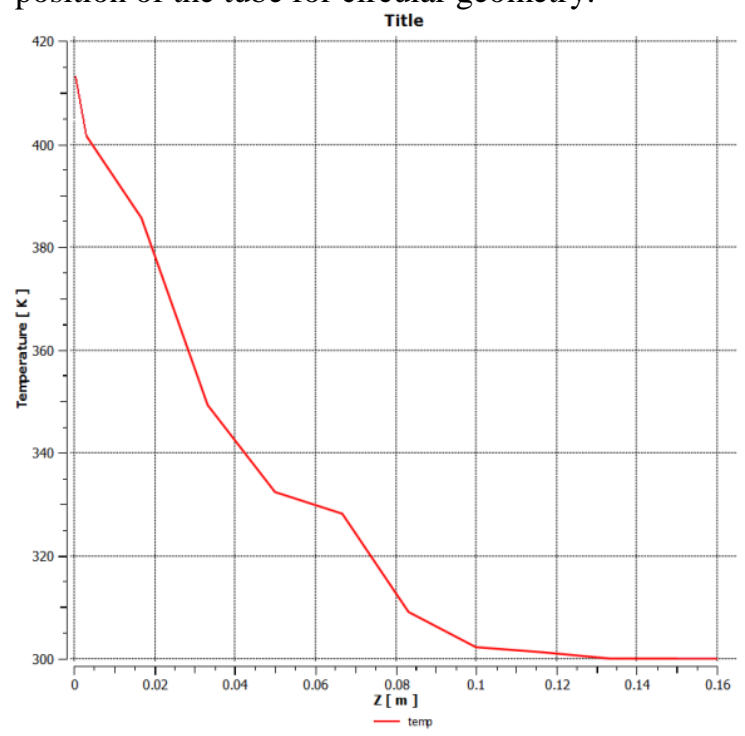

Fig. 5.3 Variation of temperature profile with the position of the tube for rectangular geometry.

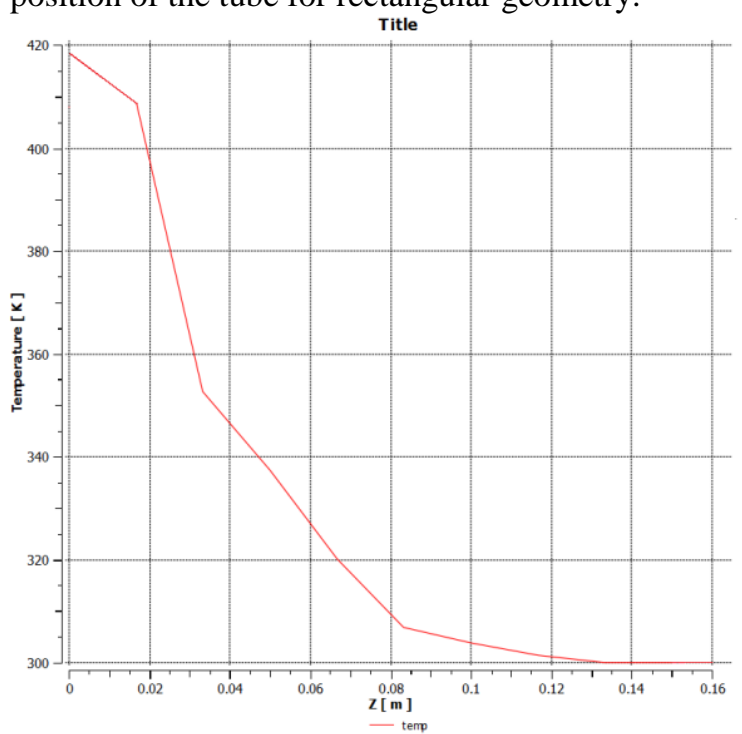

Fig. 5.4 Variation of temperature profile with the position of the tube for triangular geometry. 


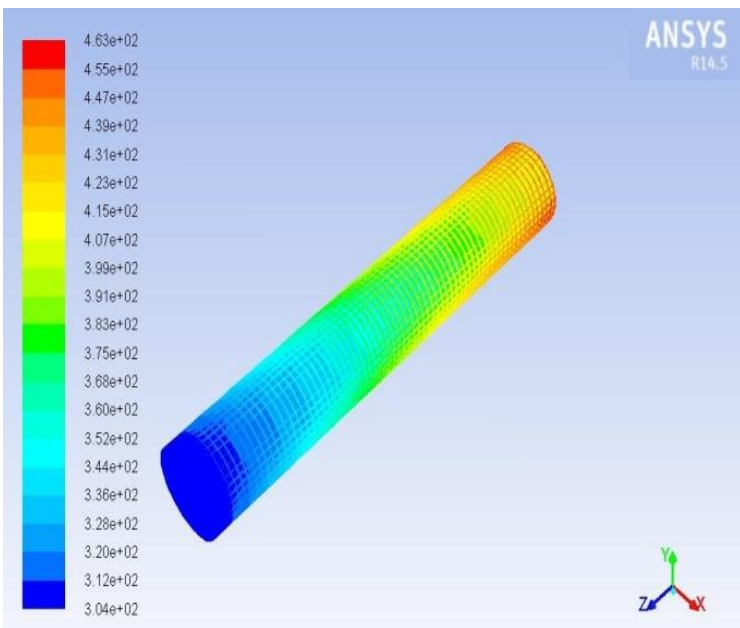

Fig. 5.5 (a) Contours of static temperature for circular geometry of the tube.

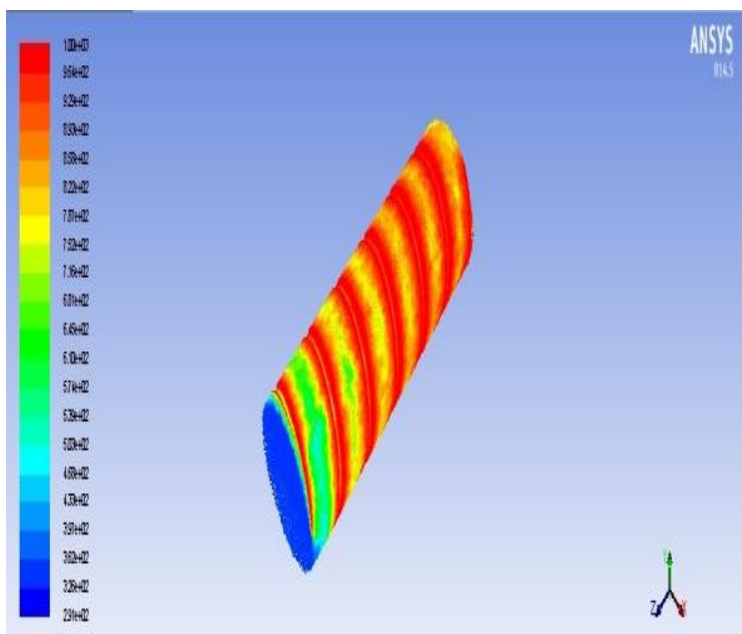

Fig. 5.5 (b) Contours of static temperature for smooth tube.

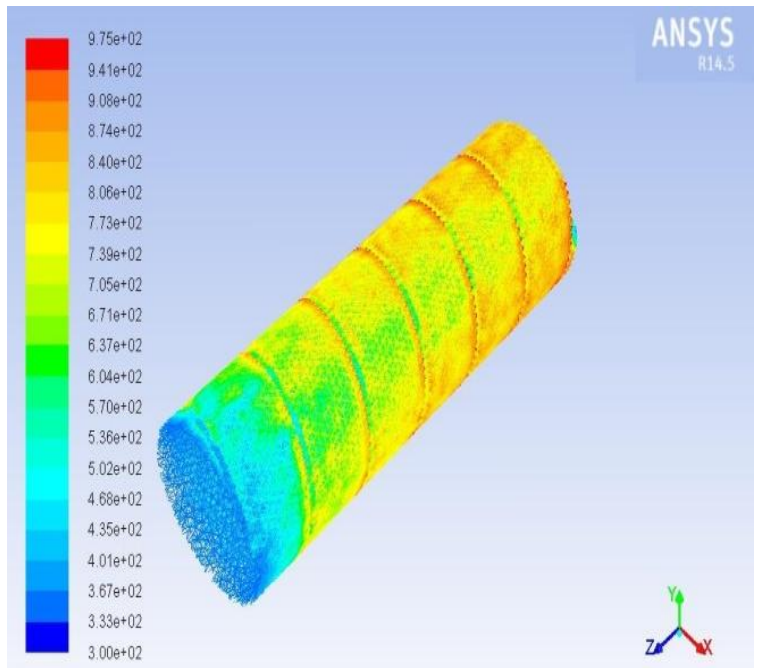

Fig. 5.5 (c) Contours of static triangular geometry of the tube.

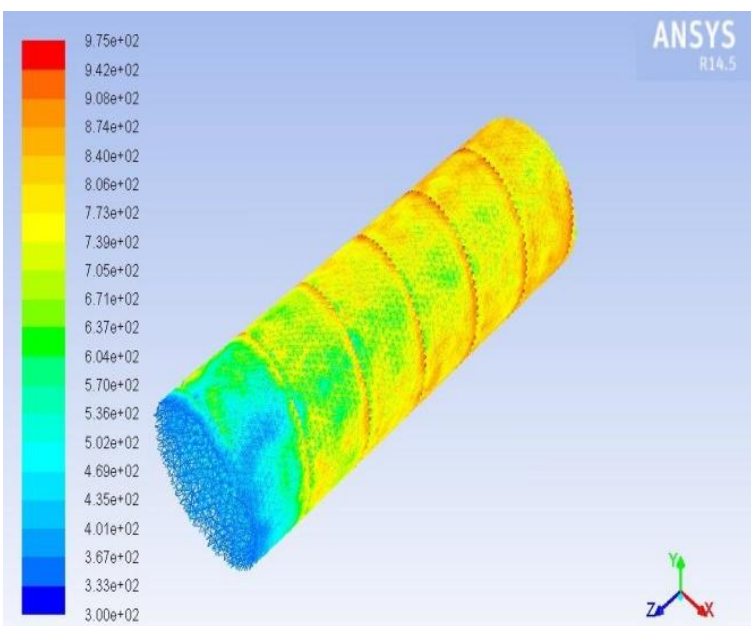

Fig. 5.5 (d) Contours of static temperature for rectangular geometry of the tube.

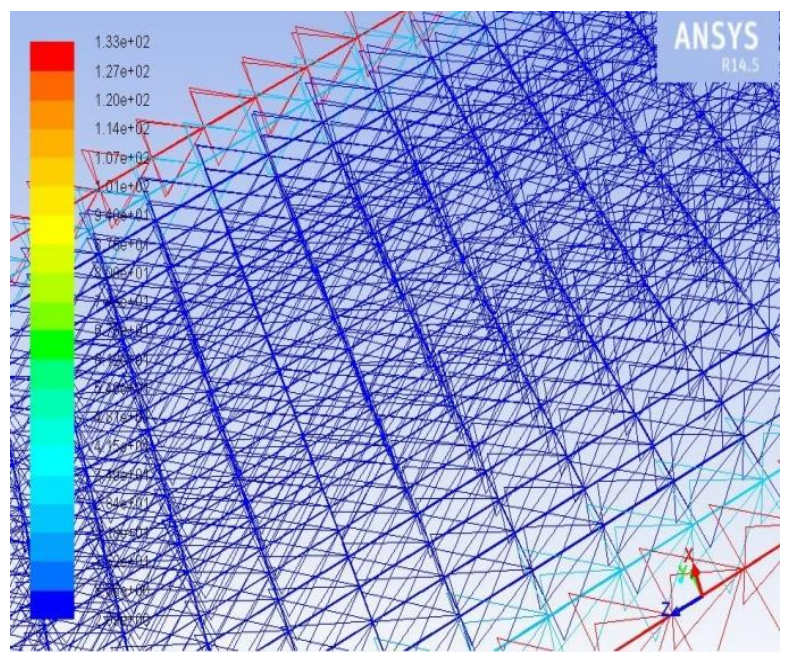

Fig. 5.6 (a) Velocity vector for smooth tube.

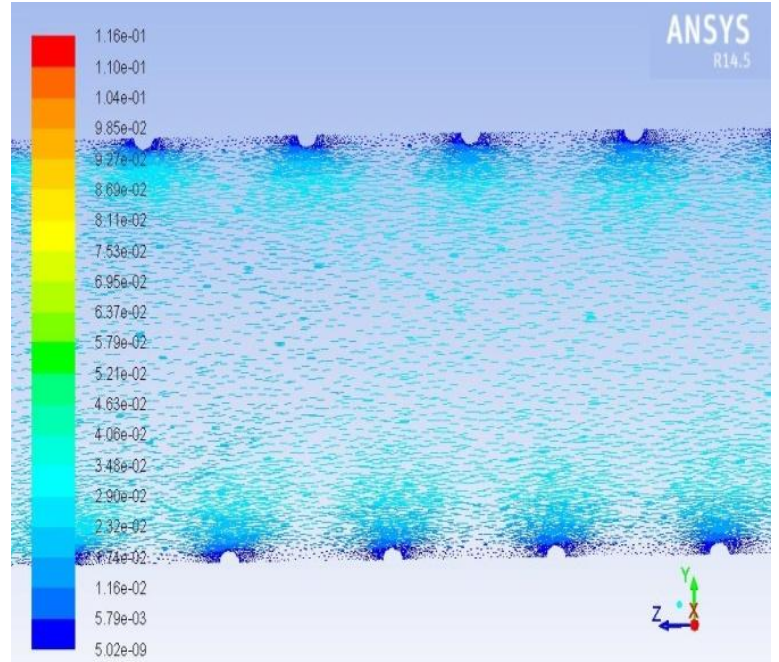

Fig. 5.6 (b) Velocity vector at the corrugation for circular tube. 


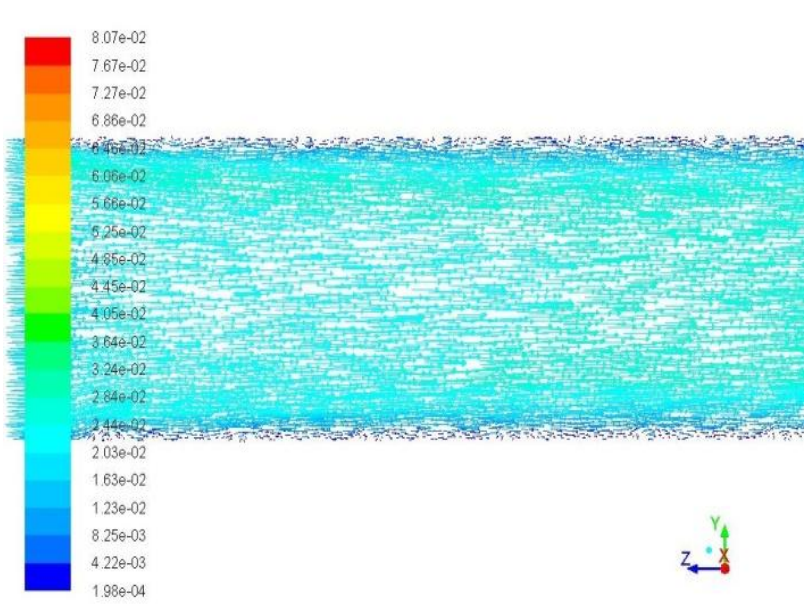

Fig. 5.6 (c) Velocity vector at the corrugation for rectangular tube.

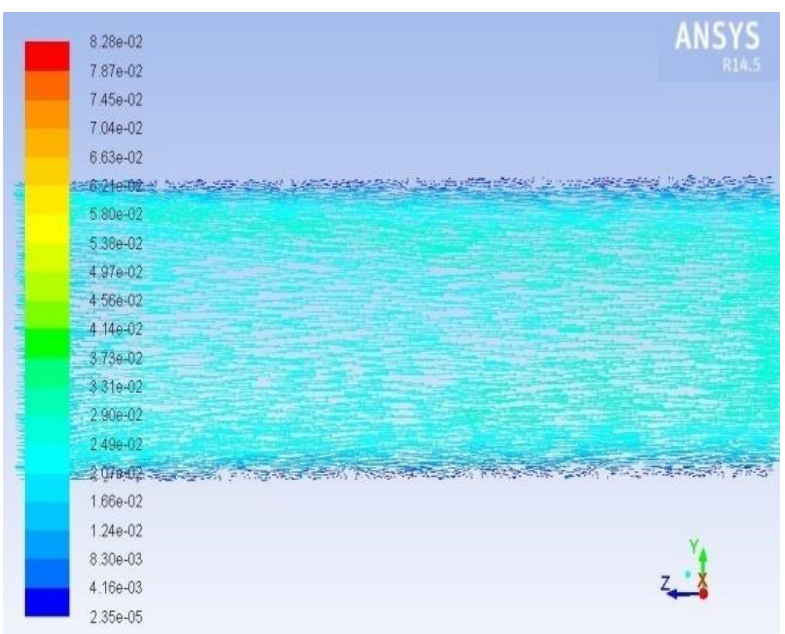

Fig. 5.6 (d) Velocity vector at the corrugation for triangular tube.

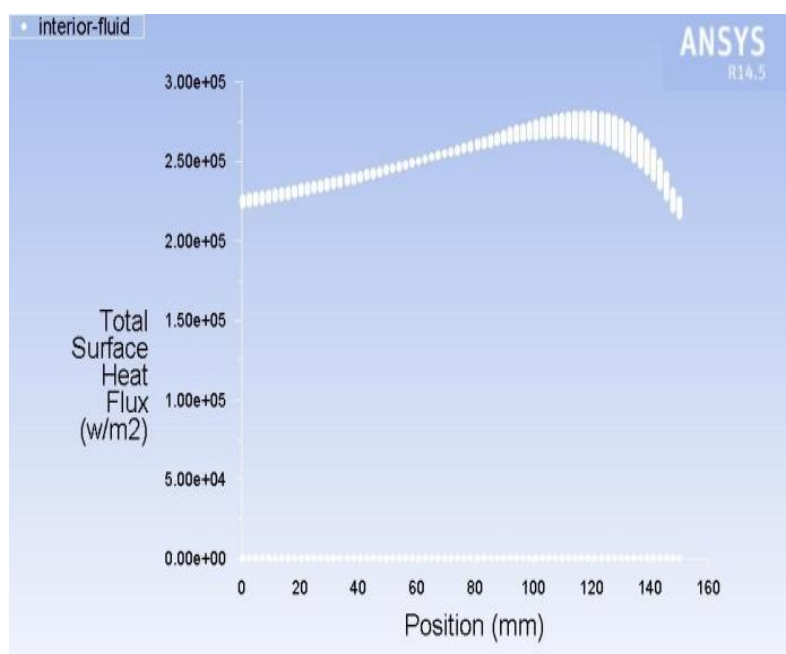

Fig. 5.7 (a) Plot of total surface heat flux for circular corrugated tube design.

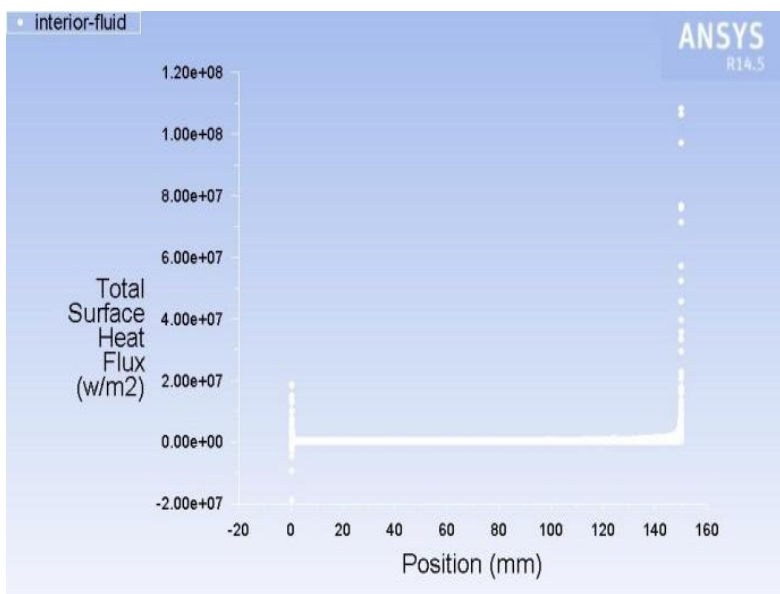

Fig. 5.7 (b) Plot of total surface heat flux for smooth tube.

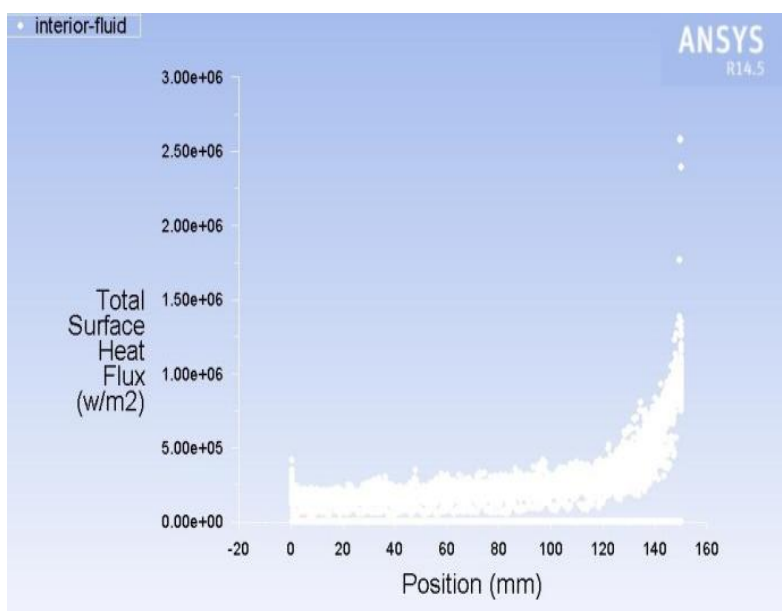

Fig. 5.7 (c) Plot of total surface heat flux for triangular corrugated tube design.

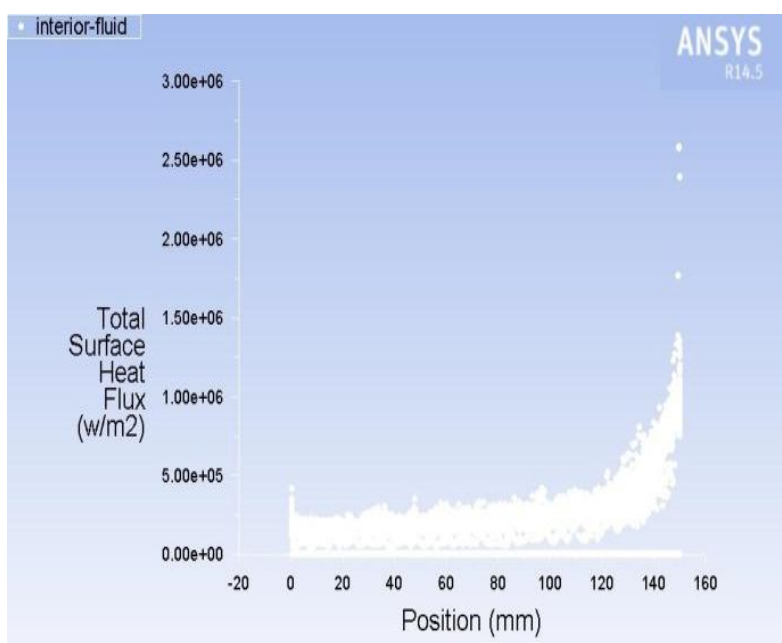

Fig. 5.7 (d) Plot of total surface heat flux for rectangular corrugated tube design. 


\section{CONCLUSION}

In this research paper, main results of the present research on plain tube, rectangular and circular corrugated shape tubes and the comparative analysis between triangular shape (based on previous research) and rectangular and circular corrugated shape tubes and scope for further study have been given. The heat transfer in the tube has been analyzed, and its dependency on geometry is reported in this study. Enhancement in the heat transfer in boiler furnace will reflect in the performance of the boiler. A small increase in the heat transfer of the tube will make huge change in the overall performance of the boiler. Sample length of the boiler tube is analyzed in the software and the resultant temperature, enthalpy contours and plots are shown in the last chapter. The heat transfer enhancement effect in corrugated channel is primarily due to induced turbulence which gives higher heat transfer rate. As shown from the study, different geometries give different results for the same flow conditions (mass-flow rate). The choice of appropriate geometry does not always depend on mass-flow rate values, but predictability and almost constant behavior through a low mass-flow rate range, plays an important role. According to the study, the choice of suitable tube geometry depends on the application. The corrugated design is shown to give better convective properties (approximately $20 \%$ more convective transfer) as the temperature of the fluid goes up to $418 \mathrm{~K}$ while the inlet temperature was $300 \mathrm{~K}$, the helical (triangular) ridging design gives better convective properties (approximately $21.33 \%$ more convective transfer) as compared to smooth tube, while circular and rectangular tube design also gives better convective properties (approximately 19\% and 20\% more convective transfer) in comparison with smooth tube. The model was created using Solid Works 2012 and meshed with Fluent, and the flow analysis is done with Ansys 14.5. The results showing that the heat transfer is increased. The enthalpy and temperature increase with flow is advancing when compare with normal boiler tube. So the implementation of Optimized Helical Ridging boiler tube in the boiler is advisable. The study shows that the improvement in furnace, heat transfer can be achieved by changing the internal plane surface to a rifled tube. In the present work it is assumed that constant mass flow rate of fluid in all the design are going through the channel respectively. In actual practice this is not the case as mass flow rate is not always constant in actual practise for the applications. Inclusion of these varying flow rates is a future scope of this present work. In place of helical ridging type geometries like crcular, rectangular, and triangular as analysed in this present work, other geometrical designs can be taken and analyzed in order to increase the heat transfer rate during the flow of fluid inside the tube. This will be an extension of this present work. Experimental work can be done in order to validate the present work, evaluated parameters. This is an another future scope of this present work.

\section{REFERENCES}

[1] Zarnett, G. D. \& Charles, M. E. (1969). Concurrent gas-liquid flow in horizontal tubes with internal spiral ribs. The Canadian Journal of Chemical Engineering, Vol. 47, pp. 238- 241.

[2] Webb, R. L. \& Kim, N. H. (2005) Principles of Enhanced Heat Transfer. Boca Raton: Taylor \& Francis.

[3] Han, J. C. et al. (1978). An Investigation of Heat Transfer and Friction for RibRoughened Surfaces. International Journal of Heat and Mass Transfer, Vol. 21, pp. 1143-1156.

[4] LinJ.H., Huang C.Y., Su C.C., "Dimensional analysis for the heat transfer characteristics in the corrugated channels of plate heat exchangers", International Communications in Heat and Mass Transfer 34 , 2007, pp.304-312.

[5] Lee, S. K. et. al. (2008). Experimental Study of Post-Dryout with R-134a Upward Flow in Smooth Tube and Rifled Tubes. International Journal of Heat and Mass Transfer, Vol. 51, pp. 3153-3163.

[6] Köhler, W. and Kastner, W. (1986). Heat transfer and pressure loss in rifled tube. Proceeding of 8th International Heat Transfer Conference, Vol. 5, pp. 28612865.

[7] Cheng, L. X. and Chen, T. K. (2006). Study of single phase flow heat transfer and friction pressure drop in a spiral internally ribbed tube. Chemical EngineeringTechnology, Vol. 29, No.5, pp. 588-595.

[8] Goldstein L, Sparrow EM. ,"Heat/mass transfer characteristics for flow in a corrugated wall channel"., Transaction of the ASME, Journal of Heat Transfer, 1997;99:187-95.

[9] O’Brian JE, Sparrow EM., "Corrugatedduct heat transfer, pressure drop, and flow visualization", Transaction of the ASME, Journal of Heat Transfer 1982; 104:410-6.

[10] Sparrow, E. M. and Comb J. W., "Effect of interwall spacing and fluid flow inlet conditions on a corrugated-wall heat exchanger", International Journal of Heat and Mass Transfer 1983; 26 (7): pp.9931005. 
[11] Ali M, RamadhyaniS.,"Experiments on convective heat transfer in corrugated channels. Experimental Heat Transfer", 1992; 5:175-93.

[12] Nishimura, T., Kajimoto, Y, and Kawamura, Y. "Mass Transfer Enhancement in Channels with a Wavy Wall," Journal of Chemical Engineering of Japsm, Vol. 19, 1986, pp. 142-144.

[13] Oyakawa, K. Shinzato, T, and Mabuchi, 1. "The Effects of the Channel Width on Heat Transfer Augmentation in a Sinusoidal Wave Channel," JSME International Journal, Series II, Vol. 32, No.3, 1989, pp. 403-410.

[14] Voelker, S. and Vanka, S. P. "Fluid Flow and Heat Transfer in Serpentine Channels at Low Reynolds Numbers," University of Illinois at Urbana-Champaign, Air Conditioning and Refrigeration Center, 1997, Technical Report ACRC TR-115.

[15] Asako Y. and Faghri M., "Finite volume solutions for laminar flow and heat transfer in a corrugated duct", Trans. ASME Journal of heat transfer, Vol. 109, 1987, pp. 627634.

[16] Asako,Y. Hiroshi Nakamura and Mohammad Faghri, "Heat transfer and pressure drop characteristics in a corrugated duct with rounded corners", International Journal of Heat and Mass Transfer, Volume 31, Issue 6, June 1988, pp. 1237-1245. 